\title{
Voltammetric Determination of Free and Total Manganese in Tea Infusions
}

\author{
Aline C. Elias, ${ }^{a}$ Silvia V. F. Castro, ${ }^{a}$ Rodrigo A. A. Muñoz ${ }^{\oplus *, a}$ and Sidnei G. Silva ${ }^{\circledR *, a}$ \\ ${ }^{a}$ Instituto de Química, Universidade Federal de Uberlândia, 38400-902 Uberlândia-MG, Brazil
}

\begin{abstract}
Tea infusions are a source of mineral nutrients, including manganese. Although it is classified as an essential element, the excess of manganese is toxic for humans and its toxicity depends on its bioavailability. In this context, we propose a simple procedure to determine free and total manganese in black tea infusions by square-wave voltammetry (SWV). Free manganese was directly quantified in the samples after simple sample dilution in $0.1 \mathrm{~mol} \mathrm{~L}^{-1}$ acetic acid/acetate buffer $(\mathrm{pH}=4.5)$ while total manganese determination was carried out after sample digestion with oxidant mixture $\left(\mathrm{HNO}_{3}+\mathrm{H}_{2} \mathrm{O}_{2}\right)$. For comparison, cloud point extraction was performed to remove organic-bound manganese and the content of free metal (not extracted) measured by flame atomic absorption spectrometry (F AAS) agrees with the values obtained by the proposed SWV procedure. The limit of detection and quantification were estimated for manganese determination as 0.06 and $0.20 \mu \mathrm{g} \mathrm{L}^{-1}$, respectively, with a linear range observed between 20 and $250 \mu \mathrm{g} \mathrm{L}^{-1}$. The coefficient of variation was $9.7 \%\left(50 \mu \mathrm{g} \mathrm{L}^{-1}, \mathrm{n}=10\right)$. The procedure was applied to determination of free and total manganese in black tea bags and the results were compared with literature procedures employing F AAS.
\end{abstract}

Keywords: fractionation, manganese, square-wave voltammetry, black tea, adsorptive stripping analysis

\section{Introduction}

Tea is an infusion originally prepared from Camellia sinensis leaves and has become popular around the world due to their health benefits, including antioxidant properties. ${ }^{1}$ Currently, it is the second most consumed drink in the world, after water. ${ }^{2}$ During manufacture process, three types of tea can be obtained from the leaves of the Camellia sinensis: green, oolong and black, which one differ in the degree of enzymatic fermentation. Black tea is the most consumed tea in the world, produced by fermenting the slightly wilted leaves, and their chemical composition is rich in polyphenolic compounds, such as catechins and theaflavins, and some inorganic ions. ${ }^{3-5}$

Infusions prepared from Camellia sinensis are also a source of mineral nutrients and some of these compounds are classified as essential element. ${ }^{5-7}$ However, manganese is the only element found in significant dietary amounts in tea, found in black tea in concentrations up to $4 \mathrm{mg} \mathrm{L}^{-18}$. According to the Food and Nutrition Board of the National Academy of Science (NAS), ${ }^{9}$ an adequate intake for manganese is $2.3 \mathrm{mg} \mathrm{day}^{-1}$ for men and $1.8 \mathrm{mg} \mathrm{day}^{-1}$ for women, and an upper limit for daily intake is $11 \mathrm{mg}$

*e-mail: munoz@ufu.br; sidgons@gmail.com for adults. Some authors ${ }^{8}$ have reported that a single cup of tea contributes about $10 \%$ of daily dietary intake of manganese, considering the bioavailable form of this metal. Although manganese is classified as an essential element, elevated metal intake has been associated with neurological diseases. ${ }^{2,10,11}$ Thus, for bioavailability or bioactivity studies it is necessary the determination of organic and inorganic metal forms. ${ }^{12}$ Speciation and fractionation analysis in food samples are difficult and there are few works in the literature for this proposal. Several challenges need to be overcome to carry out fractionation analysis, and the sample preparation step is one of the most critical steps, due to analyte stability and some interaction between reagents and samples. ${ }^{11}$

Free manganese is the major fraction present in tea infusions, and the most stable forms is $\mathrm{Mn}^{\text {II }}$. Organic fraction of this analyte is associated as a series of complexes with different stability formed with polyphenol compounds..$^{13}$ Some works ${ }^{13-15}$ are reported in the literature for manganese fractionation in the tea infusions. These procedures included solid phase ${ }^{13}$ and liquid-liquid extraction. ${ }^{14,15}$ In these procedures, organic and inorganic manganese fractions are separated from sample matrix prior analysis. Direct determination of the manganese forms in tea is difficult due to a great number of concomitant species. ${ }^{13}$ In all works related to manganese fractionation, 
flame atomic absorption spectrometry (F AAS) was employed for analyte quantification.

Electrochemical measurements are an alternative for spectrometric manganese determination in food samples. ${ }^{16}$ Additional advantage of electroanalysis is the possibility of direct detection of labile metallic species in solution as demonstrated in natural waters. ${ }^{17-19}$ Considering tea samples, some organic species, such as polyphenolic compounds, form strong and non-electroactive complexes with manganese, ${ }^{17}$ while a small fraction of manganese is free (labile) in solution and bioavailable when tea is consumed.

In this work, we propose a square-wave voltammetry (SWV) employing a glassy-carbon electrode for the direct detection of free manganese in tea samples after sample dilution in electrolyte. SWV was also proposed to determine the total manganese concentration after sample digestion.

\section{Experimental}

\section{Chemicals and reagents}

Manganese reference solutions were prepared by diluting a single-element $1000 \mathrm{mg} \mathrm{L}{ }^{-1}$ (plus $\mathrm{HNO}_{3}$ $0.5 \mathrm{~mol} \mathrm{~L}^{-1}$ ) stock solution (Merck, Darmstadt, Germany) in distilled-deionized water $(18.2 \mathrm{M} \Omega \mathrm{cm}$, Milli-Q, Gehaka, Brazil). $0.1 \mathrm{~mol} \mathrm{~L}^{-1}$ acetate buffer solution $(\mathrm{pH}=4.5)$ was prepared by dissolving appropriate amounts of acetic acid (Merck, Darmstadt, Germany) and sodium acetate (Merck, Darmstadt, Germany) in deionized water. Concentrated nitric acid (Merck, Darmstadt, Germany) and hydrogen peroxide $30 \% \mathrm{~m} \mathrm{~m}^{-1}$ (Merck, Darmstadt, Germany) were employed for sample digestion.

\section{Apparatus}

Electrochemical measurements employing cyclic voltammetry and SWV were performed using a potentiostat/galvanostat (Vertex, Ivium, Eindhoven, Netherlands) interfaced to a microcomputer and controlled by IviumSoft 2.5 software. A mini $\mathrm{Ag} / \mathrm{AgCl} / \mathrm{KCl}_{\text {sat }}$ and a platinum wire were used as the reference and auxiliary electrodes, respectively. A glassy carbon electrode (BASi, West Lafayette, USA) of $1.6 \mathrm{~mm}$ diameter was used as working electrode in all measurements.

\section{Sample preparation}

Black tea was prepared according to manufacturer's instructions. A tea bag (ca. $2 \mathrm{~g}$ ) was placed in $500 \mathrm{~mL}$
Pyrex ${ }^{\circledR}$ Erlenmeyer flask and $200 \mathrm{~mL}$ of hot deionized water $\left(100{ }^{\circ} \mathrm{C}\right)$ was added. After this, the sample was left to cool for $10 \mathrm{~min}$ and filtered $(0.45 \mu \mathrm{m}$ cellulose acetate membranes) and kept under refrigeration until measurements.

For free manganese determination, measurements were carried out after sample dilution (100-fold) in $0.1 \mathrm{~mol} \mathrm{~L}^{-1}$ acid acetic/acetate buffer $(\mathrm{pH}=4.5)$. Total manganese determination was performed after acid digestion employing $3 \mathrm{~mL}$ of black tea infusion, $1 \mathrm{~mL}$ of concentrated nitric acid plus $0.25 \mathrm{~mL}$ of $30 \% \mathrm{~m} \mathrm{~m}^{-1}$ hydrogen peroxide, under heating for $1 \mathrm{~h}\left(90{ }^{\circ} \mathrm{C}\right)$ in an aluminum heating block. Subsequently, the digest was diluted 50-fold with $0.1 \mathrm{~mol} \mathrm{~L}^{-1}$ acetic acid/acetate buffer followed by the measurements. The method of standard addition was used for all quantification procedures.

\section{Results and Discussion}

\section{Fundamentals of the method}

Some works have been reported in the literature ${ }^{16-22}$ for manganese determination in different sample matrices by electrochemical techniques. Manganese measurements by cathodic stripping voltammetry are based on the formation of metal oxides $\left(\mathrm{MnO}_{2}\right)$ which absorb on the carbon electrode surface followed by metal reduction. ${ }^{23,24}$ The first electrochemical reduction process involves one proton and one electron with the formation of $\mathrm{MnOOH}$. A second reduction process of $\mathrm{MnOOH}$ leading to $\mathrm{Mn}^{2+}$ and $\mathrm{H}_{2} \mathrm{O}$ occurs at less positive potentials in a step involving three protons and one electron..$^{25}$ These applications are based on free manganese determination in the absence of organic species, specifically ligand molecules. In the presence of chelating agents, some stable complexes can form with different electrochemical profile. In this work, all optimization procedure were conducted using free manganese species, $\mathrm{Mn}^{\mathrm{II}}$, and the first electrochemical reduction, as this process provided a more intense and stable current response.

\section{Optimization of electrochemical conditions}

Voltammetric manganese measurements are favored in slightly acidic media, in this way acetate/acetic acid buffer $\left(0.1 \mathrm{~mol} \mathrm{~L}^{-1}, \mathrm{pH}=4.5\right)$ was used as supporting electrolyte based on the previous literature studies. ${ }^{25}$ This $\mathrm{pH}$ value is close to the samples analyzed in this work and the values reported in the literature. ${ }^{26}$ This parameter is important to ensure analyte stability in the sample determination, avoiding equilibrium shift for manganese complexes present in the 
sample. The electrochemical parameters of square-wave voltammetry can directly influence the analytical signal. Several electrochemical parameters were optimized by the univariate method with the purpose of obtaining a commitment relationship between analytical response, precision and selectivity for the determination of manganese in infusions prepared from the Camellia sinensis.

The effect of pulse amplitude for manganese determination was evaluated in the range of 10 to $100 \mathrm{mV}$ (Figures $1 \mathrm{a}$ and $1 \mathrm{~b})$. The increase in amplitude $(\mathrm{mV})$ contributed to enhance the voltammetric response. Thus, $100 \mathrm{mV}$ was selected for further studies. The frequency of application of the potential pulses was evaluated in the range of 10 to $100 \mathrm{~Hz}$, according to Figure 1c, and the analytical signal increased with increasing frequency (Figure 1d). However, for values above $60 \mathrm{~Hz}$, greater deviations were observed. The increase in frequency causes an increase in the sputtering of the $\mathrm{Mn}^{\mathrm{II}}$ cathodic solution
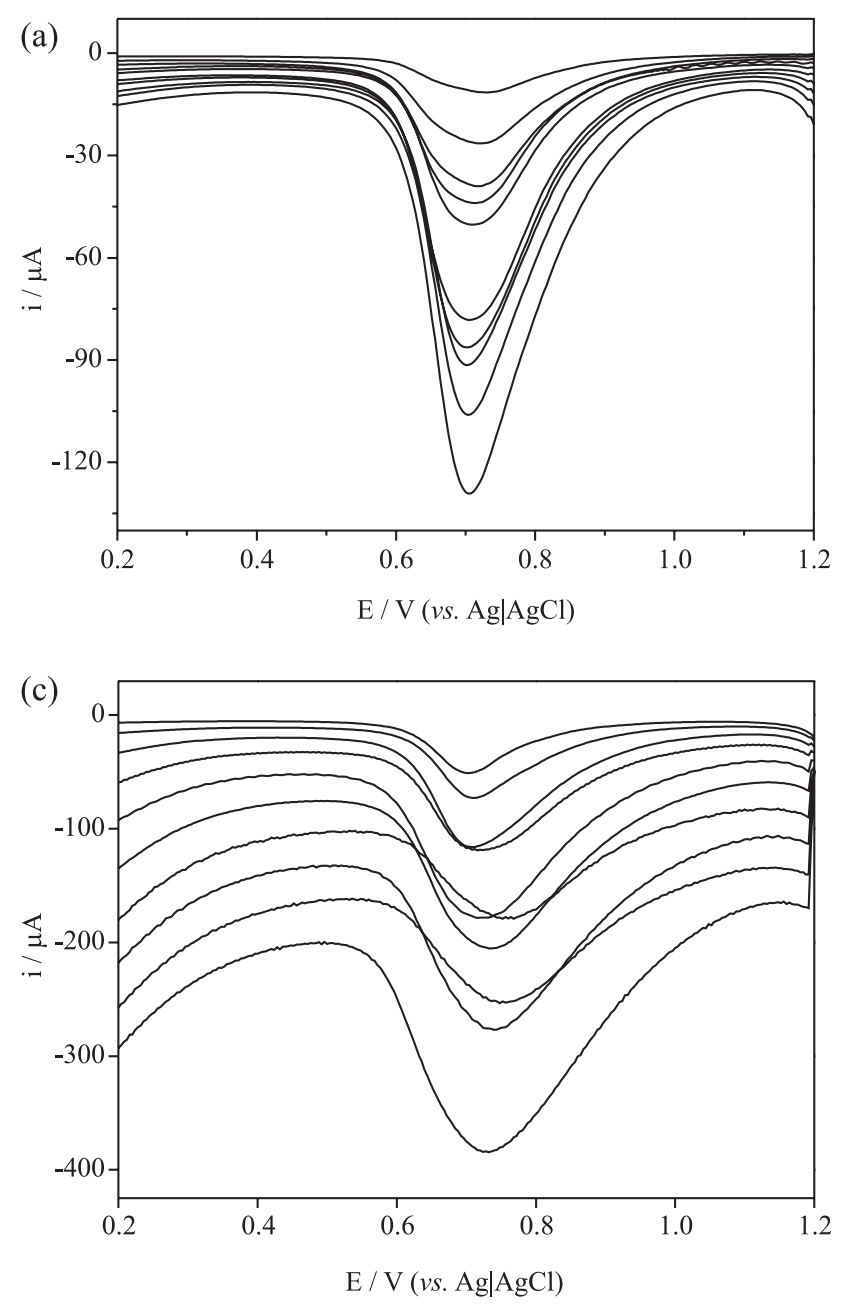

and may lead to an overlapping of other peaks having the signal close to $\mathrm{Mn}^{\mathrm{II}}$ (Figure 1c). Considering these aspects, the frequency of $60 \mathrm{~Hz}$ was selected for later studies. The step potential was evaluated in the range of 1 to $10 \mathrm{mV}$ and no significant differences in analytical signal were observed (Figure 2a). Considering only the smallest standard deviation, better results were obtained when the increase of $2 \mathrm{mV}$ was employed, providing better accuracy in measurements (Figure 2b).

An alternative to increase the sensitivity in voltammetric measurements is to increase the stirring time during the application of a deposition potential, resulting in mass transport by convection next to the surface of the electrode. The longer deposition time leads to greater metal deposition on electrode surface..$^{27}$ The effect of deposition time was evaluated in the range of 0 to $200 \mathrm{~s}$ and the results obtained are shown in Figure 2c. As can be seen in Figure 2d, the analytical signal increases with increasing deposition
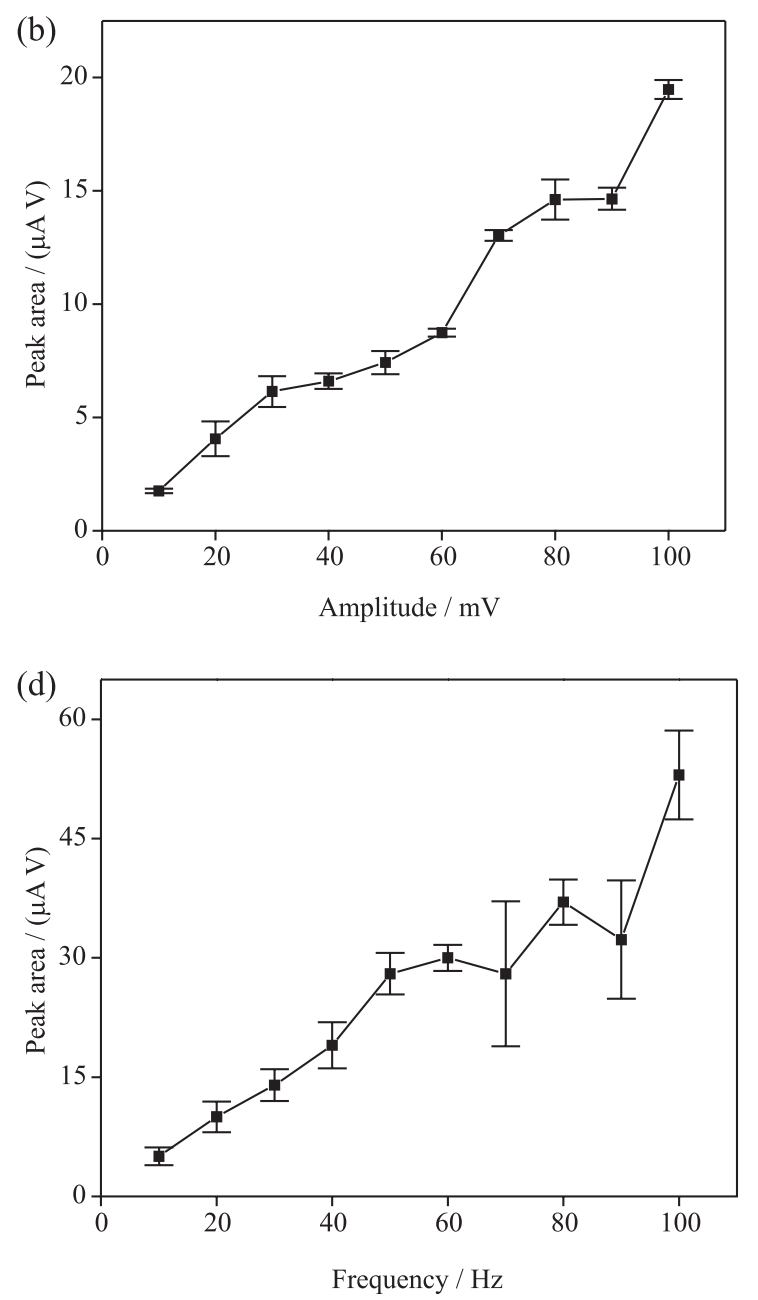

Figure 1. Effect of $(a, b)$ amplitude potential and $(c, d)$ frequency on the square-wave voltammetric detection of manganese. Square-wave cathodic stripping voltammetry (SWCSV) parameters in (a): $2000 \mathrm{rpm}$ (stirring rate); $60 \mathrm{~s}$ (deposition time); $30 \mathrm{~s}$ (conditioning time); $-0.5 \mathrm{~V}$ (conditioning potential); $4 \mathrm{mV}$ (step potential); $1.2 \mathrm{~V}$ (deposition potential); $20 \mathrm{~Hz}$ (frequency). All the optimizations were made utilizing $0.1 \mathrm{~mol} \mathrm{L^{-1 }}$ acetic acid/acetate buffer ( $\mathrm{pH} 4.5$ ) as background electrolyte containing $50 \mu \mathrm{g} \mathrm{L}^{-1}$ of $\mathrm{Mn}^{2+}$. 

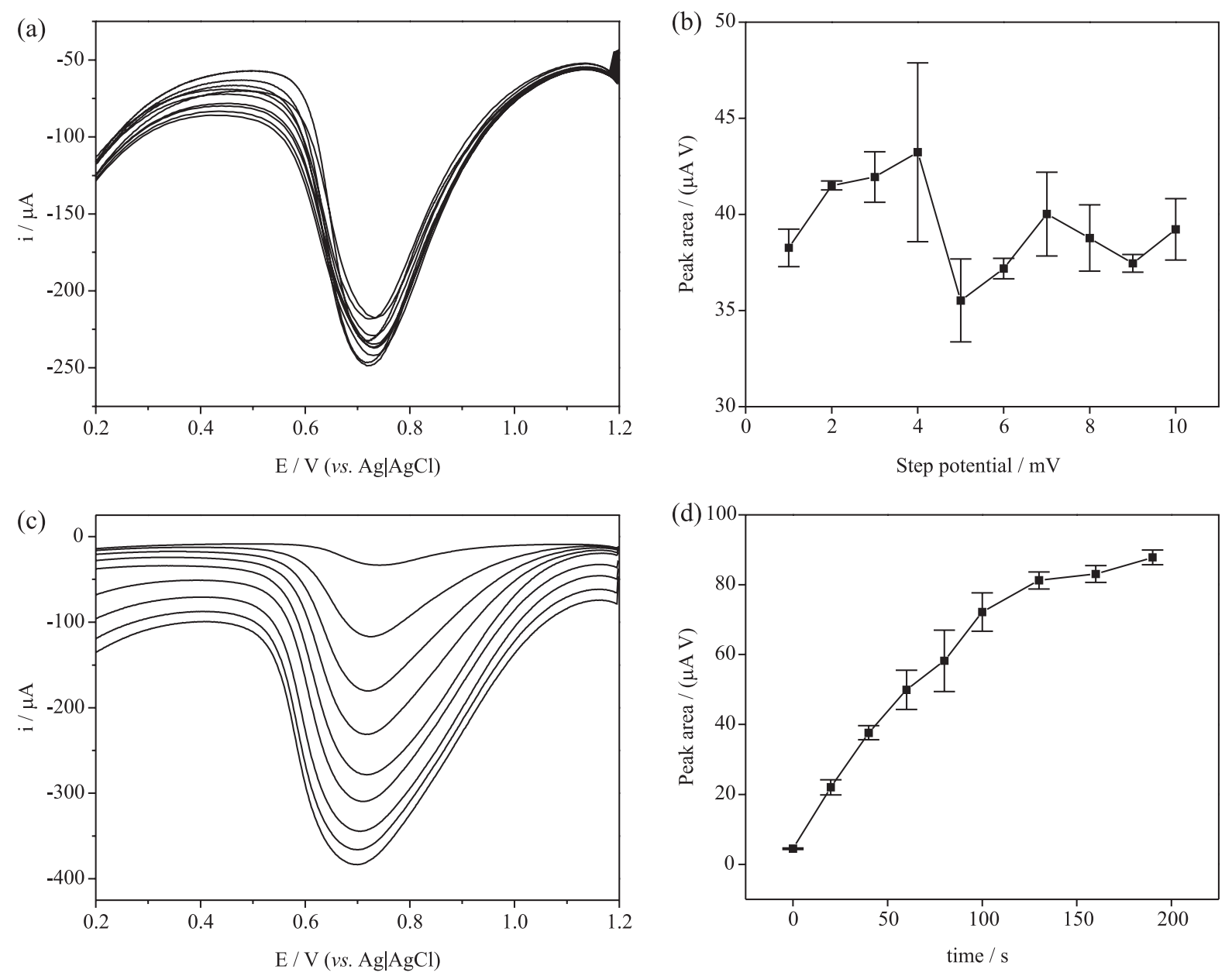

Figure 2. Effect of $(a, b)$ step potential and $(c, d)$ deposition time on the square-wave voltammetric detection of manganese. Square-wave cathodic stripping voltammetry (SWCSV) parameters in (a): $2000 \mathrm{rpm}$ (stirring rate); $60 \mathrm{~s}$ (deposition time); $30 \mathrm{~s}$ (conditioning time); $-0.5 \mathrm{~V}$ (conditioning potential); $4 \mathrm{mV}$ (step potential); $1.2 \mathrm{~V}$ (deposition potential). All the optimizations were made utilizing $0.1 \mathrm{~mol} \mathrm{~L}^{-1}$ acetic acid/acetate buffer ( $\mathrm{pH} 4.5$ ) as background electrolyte containing $50 \mu \mathrm{g} \mathrm{L}-1$ of $\mathrm{Mn}^{2+}$.

time. Seeking to establish a commitment relationship between signal increase and analytical frequency, the time of $90 \mathrm{~s}$ was selected for further studies. Table 1 presents the optimized parameters and the values selected for the voltammetric determination of manganese.

\section{Analytical features}

Calibration curves were obtained by manganese reference solution under optimized conditions. A concentration range from $20-600 \mu \mathrm{g} \mathrm{L} \mathrm{L}^{-1}$ was evaluated and satisfactory linearity was observed between 20 and $250 \mu \mathrm{g} \mathrm{L}{ }^{-1}$, described by the equation $\mathrm{A}_{\mathrm{Mn}}=0.21 \mathrm{C}_{\mathrm{Mn}^{\mathrm{I}}}+1.30$, in which, $\mathrm{A}_{\mathrm{Mn}}$ represents the peak area of manganese and $\mathrm{C}_{\mathrm{Mn}^{\mathrm{II}}}$ the concentration of manganese in $\mu \mathrm{L} \mathrm{L}^{-1}$. Figure 3 shows the voltammetric measurements (Figure 3a) and the respective calibration curve (Figure 3b). A desirable level of linearity, with a correlation coefficient of 0.999 , was obtained by this calibration curve. The limit of detection
Table 1. Optimized square-wave voltammetry parameters in working range 1.0 to $1.5 \mathrm{~V}$

\begin{tabular}{lc}
\hline Optimized parameter & SWCSV \\
\hline Conditioning potential / V & -0.5 \\
Conditioning time / s & 30 \\
Deposition potential / V & +1.2 \\
Deposition time / s & 90 \\
Amplitude / mV & 100 \\
Frequency / Hz & 60 \\
Step / mV & 2 \\
Supporting electrolyte & HAc/Ac \\
pH & 4.5 \\
\hline
\end{tabular}

SWCSV: square-wave cathodic stripping voltammetry.

(LOD) and the limit of quantification (LOQ) were estimated as 0.06 and $0.20 \mu \mathrm{g} \mathrm{L}{ }^{-1}$, respectively. The repeatability of the proposed method, expressed as coefficient of variation 

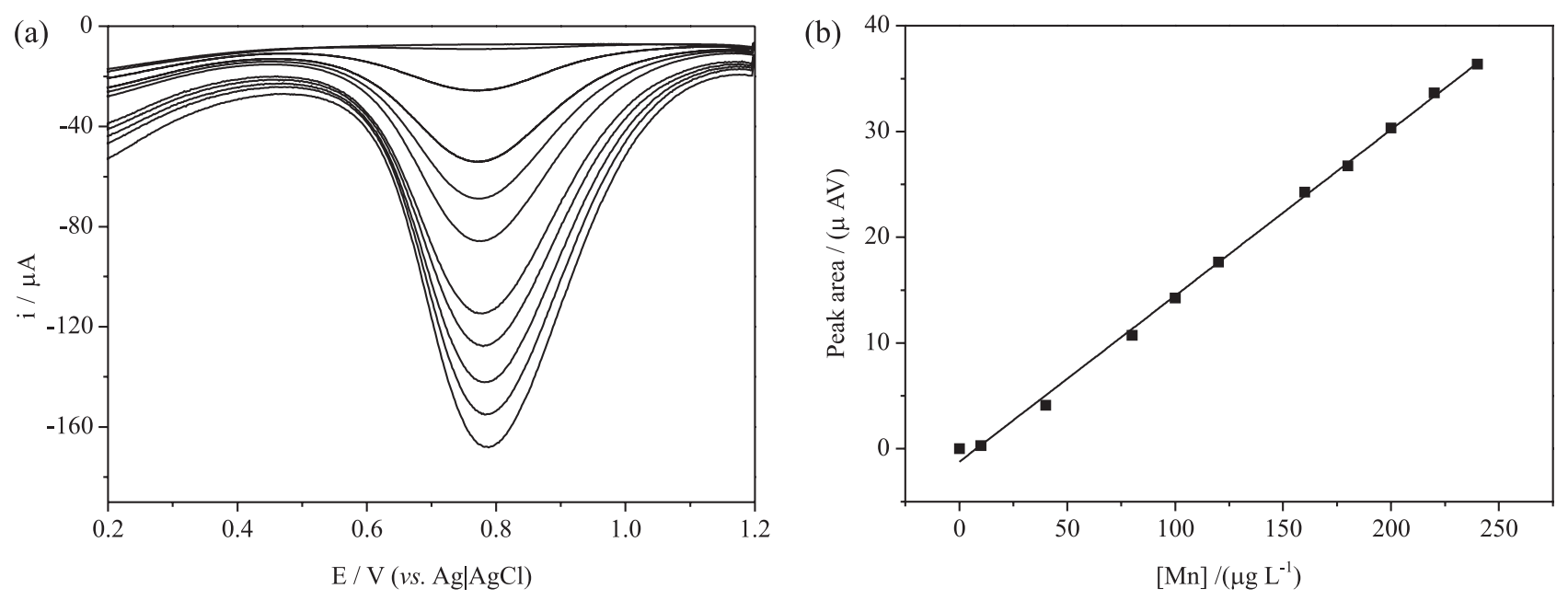

Figure 3. (a) Square-wave voltammograms of blank and after additions of manganese standard solutions in the concentration range from 10 to $250 \mu \mathrm{g} \mathrm{L}^{-1}$; (b) respective calibration curve. Conditions in Table 1.

(CV), was estimated by ten consecutive aqueous standards $\left(50 \mu \mathrm{g} \mathrm{L}^{-1}\right)$, and $\mathrm{CV}$ values was found to be $9.7 \%$.

\section{Application}

Three black tea samples were prepared according to manufacturer's recommendations. The manganese quantification was carried out by the method of standard addition after proper dilution and the results were compared to those obtained by F AAS. In all samples the results obtained by the proposed method were lower than those obtained by FAAS, which indicates that the voltammetric procedure detected free $\mathrm{Mn}^{\mathrm{II}}$ species in the samples while the F AAS method determined the total manganese content. Infusion prepared by black tea are rich in organic compounds, such as flavonoids, and some of this species could react with manganese to form some complexes.

Voltammetric measurements are suitable for metal determination in complexes matrices, including food samples ${ }^{16}$ However, some organic compounds can influence the results, causing negative interference. Some authors ${ }^{17}$ reported that $\mathrm{Mn}^{\mathrm{II}}$ ions can form strong complexes in the presence of organic substances, such as flavonoids, humic and fulvic acids. Black tea is rich in these compounds, ${ }^{3,28}$ and the complexes formed with $\mathrm{Mn}^{\mathrm{II}}$ are non-electroactive. ${ }^{17}$ Due to this, complete destruction of the organic substance is recommended before electrochemical measurements in order to detect the total content of manganese.

Thus, a sample preparation step was implemented for sample digestion. For this, $3 \mathrm{~mL}$ of sample, $1 \mathrm{~mL}$ of concentrated $\mathrm{HNO}_{3}$ and $0.25 \mathrm{~mL}$ of $\mathrm{H}_{2} \mathrm{O}_{2}(30 \% \mathrm{v} / \mathrm{v})$ were added directly in a flask heating. The mixtures were heated at $90{ }^{\circ} \mathrm{C}$ in an aluminum hot block and the digestion was carried out for $1 \mathrm{~h}$. Then the digests were diluted 50-fold in the electrolytic cell with acetic acid buffer $\left(0.1 \mathrm{~mol} \mathrm{~L}^{-1}\right.$, $\mathrm{pH}=4.5$ ). Manganese determination was carried out applying the developed procedure after sample digestion for three black tea infusions. The results were compared with those obtained by use of F AAS. The results in the Table 2 agreed at the 95\% confidence level applying the two-sample $t$-test $\left(t=0.587\right.$ and $p$-value $\left.=0.588, t_{\text {critical }}=4.303\right)$ for total manganese determination. The $F$-test at the $95 \%$ confidence level indicated that the variances of the proposed and reference methods are comparable. Therefore, after performing the sample preparation step, the voltammetric method was capable to quantify the total manganese content in the tea samples accurately.

Table 2. Mean values and uncertainties $(n=3)$ for determination of total manganese in black tea samples

\begin{tabular}{lccc}
\hline \multirow{2}{*}{ Sample } & \multicolumn{3}{c}{ Total manganese / $\left(\mathrm{mg} \mathrm{L}^{-1}\right)$} \\
\cline { 2 - 4 } & Proposed procedure & Reference & $F^{\mathrm{a}}$ \\
\hline 1 & $3.28 \pm 0.13$ & $3.42 \pm 0.20$ & 0.42 \\
2 & $3.05 \pm 0.23$ & $3.29 \pm 0.13$ & 3.13 \\
3 & $2.43 \pm 0.17$ & $2.66 \pm 0.15$ & 1.28 \\
${ }^{\mathrm{a}} F_{\text {critical }}=19(95 \%$ confidence level $)$.
\end{tabular}

Yalçın et al.${ }^{15}$ proposed a procedure for free manganese determination after cloud point extraction, in which, after extraction procedure, the manganese complexes were extracted to the rich phase and free manganese remained in the solution. To compare the obtained results in directly free manganese determination by voltammetry, the samples were submitted to cloud point extraction, removing the manganese complexes species from the aqueous solution. The aqueous phase was then submitted to the manganese determination by F AAS, which would 

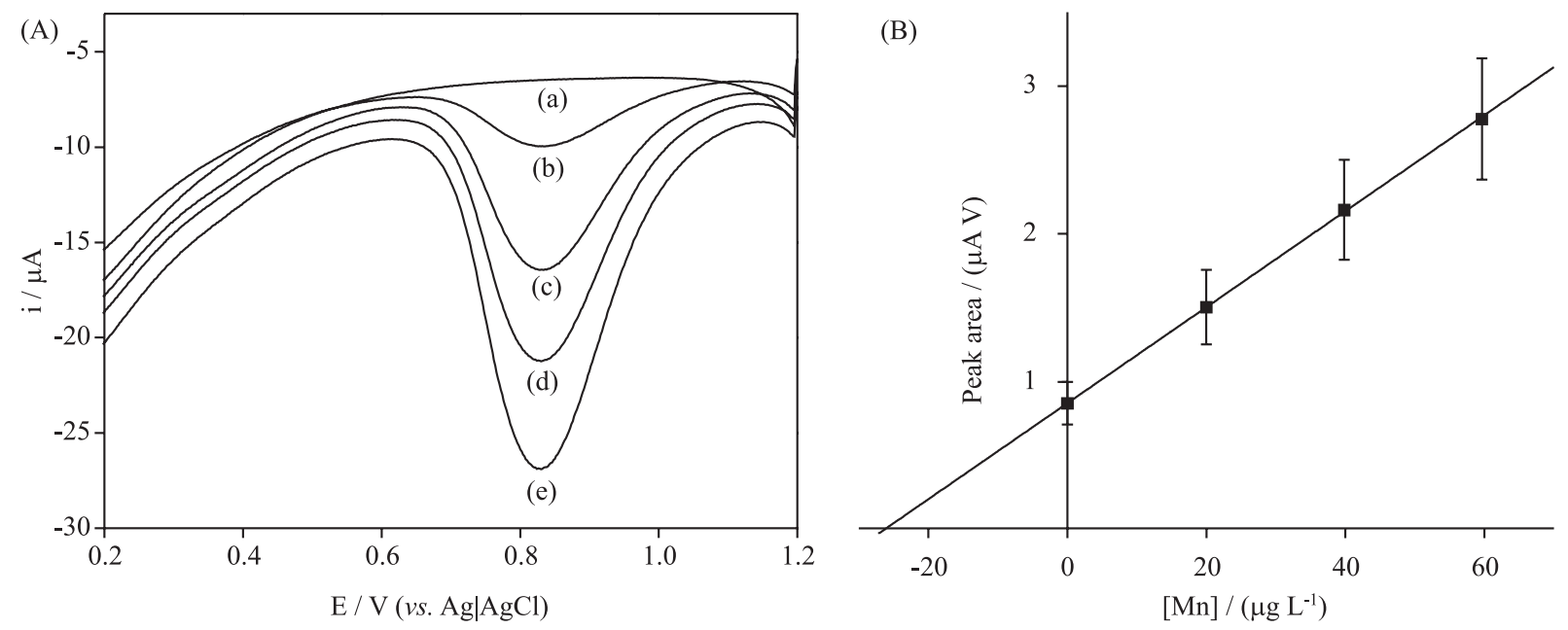

Figure 4. (A) Square-wave voltammograms for (a) blank; (b) sample 1; and after the addition of (c) 20; (d) 40; (e) $60 \mu$ g L $\mathrm{L}^{-1}$ of manganese standard solutions; (B) respective calibration curve. Experimental conditions defined in Table 1.

lead to the concentration of free $\mathrm{Mn}^{\mathrm{II}}$ species in the tea sample. The results in Table 3 agreed at the $95 \%$ confidence level applying the two-sample $t$-test $(t=-0.323$ and $p$-value $\left.=0.764, t_{\text {critical }}=4.303\right)$ for free manganese determination. Hence, the proposed voltammetric procedure enables the quantification of free $\mathrm{Mn}^{\mathrm{II}}$ in tea samples after simple sample dilution in electrolyte. The proposed procedure does not require a laborious sample treatment, such as cloud point extraction, to obtain the concentration of free $\mathrm{Mn}^{\mathrm{II}}$ species in such a complex sample. Figure 4 shows square-wave voltammograms for increased concentrations of $\mathrm{Mn}^{\mathrm{II}}$ in sample 1 and the respective calibration curve. As can be seen, no peak alteration occurred in the manganese reduction signals, indicating the absence of matrix effect.

Table 3. Mean values and uncertainties $(n=3)$ for determination of free manganese in black tea samples

\begin{tabular}{lccc}
\hline \multirow{2}{*}{ Sample } & \multicolumn{3}{c}{ Free manganese / $\left(\mathrm{mg} \mathrm{L}^{-1}\right)$} \\
\cline { 2 - 4 } & Proposed procedure & Reference & $F^{\mathrm{a}}$ \\
\hline 1 & $1.09 \pm 0.22$ & $1.05 \pm 0.10$ & 4.84 \\
2 & $0.92 \pm 0.14$ & $1.00 \pm 0.10$ & 1.96 \\
3 & $0.93 \pm 0.20$ & $0.95 \pm 0.28$ & 0.51 \\
\hline
\end{tabular}

${ }^{\mathrm{a}} F_{\text {critical }}=19$ (95\% confidence level).

\section{Conclusions}

A novel analytical procedure was developed for free and total manganese in black tea infusions exploiting cathodic stripping square-wave voltammetry. Advantages of the proposed procedure include direct free manganese determination, after simple sample dilution; small instrumentation devices when compared to measurements by atomic absorption spectrometry; and it is suitable for determination of free and total manganese in tea samples. Additionally, the developed procedure also enables the determination of total manganese after sample digestion with a mixture of nitric acid and hydrogen peroxide. The analytical features are comparable with those obtained by the spectrophotometric procedures nevertheless with a significant reduction of sample consumption.

\section{Acknowledgments}

The authors would like to thank the financial support from National Council for Scientific and Technological Development (CNPq, process number: 425494/2018-7, 307271/2017-0 and 465389/2014-7-INCTBio) and Coordination for the Improvement of Higher Education Personnel (CAPES, financial code 001). Support from the Minas Gerais State Agency for Research and Development (FAPEMIG) is greatly appreciated.

\section{References}

1. Konieczynski, P.; Viapiana, A.; Wesolowski, M.; Food Anal. Methods 2017, 10, 3063.

2. Sanlier, N.; Gokcen, B. B.; Altuğ, M.; Trends Food Sci. Technol. 2018, 78, 95.

3. Harbowy, M. E.; Balentine, D. A.; Davies, A. P.; Cai, Y.; Crit. Rev. Plant Sci. 1997, 16, 415.

4. Ferrara, L.; Montesano, D.; Senatore, A.; Trends Cognit. Sci. 2004, 8, 170.

5. Yemane, M.; Chandravanshi, B. S.; Wondimu, T.; Food Chem. 2008, 107, 1236.

6. Martín-Domingo, M. C.; Pla, A.; Hernández, A. F.; Olmedo, P.; Navas-Acien, A.; Lozano-Paniagua, D.; Gil, F.; J. Food Compos. Anal. 2017, 60, 81. 
7. Zhao, H.; Yu, C.; Li, M.; J. Food Compos. Anal. 2017, 63, 15.

8. Powell, J. J.; Burden, T. J.; Thompson, R. P. H.; Analyst 1998, 123, 1721.

9. Institute of Medicine, Food and Nutrition Board; Dietary Reference Intakes (DRIs): Recommended Dietary Allowances and Adequate Intakes Vitamins; National Academies Press: Washington, DC, 2011.

10. Schwalfenberg, G.; Genuis, S. J.; Rodushkin, I.; J. Toxicol. 2013, 2013, 8 .

11. Grygo-Szymanko, E.; Tobiasz, A.; Walas, S.; TrAC, Trends Anal. Chem. 2016, 80, 112.

12. Flaten, T. P.; Coord. Chem. Rev. 2002, 228, 385.

13. Pohl, P.; Prusisz, B.; Food Chem. 2007, 102, 1415.

14. Wen, S.; Zhu, X.; Food Anal. Methods 2014, 7, 291.

15. Yalçın, S.; Filik, H.; Apak, R.; J. Anal. Chem. 2012, 67, 47.

16. Locatelli, C.; Electroanalysis 2004, 16, 1478.

17. Viltchinskaia, E. A.; Zeigman, L. L.; Garcia, D. M.; Santos, P. F.; Anal. Lett. 1995, 28, 1845.

18. Roitz, J. S.; Bruland, K. W.; Anal. Chim. Acta 1997, 344, 175.

19. Abollino, O.; Aceto, M.; Sacchero, G.; Sarzanini, C.; Mentasti, E.; Anal. Chim. Acta 1995, 305, 200.
20. Di, J.; Zhang, F.; Talanta 2003, 60, 31.

21. Deng, W.; Li, Y.; Electrochim. Acta 2018, 265, 265.

22. Saterlay, A. J.; Foord, J. S.; Compton, R. G.; Analyst 1999, 124 , 1791.

23. Nijjer, S.; Thonstad, J.; Haarberg, G. M.; Electrochim. Acta 2000, 46, 395.

24. Rodrigues, S.; Munichandraiah, N.; Shukla, A. K.; J. Appl. Electrochem. 1998, 28, 1235.

25. Lima, F. F.; Tormin, T. F.; Richter, E. M.; Muñoz, R. A. A.; Microchem. J. 2014, 116, 178.

26. Rugg-Gunn, A.; Br. Dent. J. 2001, 190, 370.

27. Wang, J.; Analytical Electrochemistry, $3^{\text {rd }}$ ed.; Wiley-VCH: New York, 2006.

28. Tan, J.; Engelhardt, U. H.; Lin, Z.; Kaiser, N.; Maiwald, B.; J. Food Compos. Anal. 2017, 57, 8.

Submitted: October 29, 2019 Published online: March 5, 2020 